\section{Cândido de Mello Leitão: as ciências biológicas \\ e a valorização da natureza e da diversidade da vida}

\author{
Cândido de Mello \\ Leitão: the biological \\ sciences and the \\ valorization of nature \\ and diversity of life
}

José Luiz de Andrade Franco SQN 394 Bloco D, apto. 507 70736-040 Brasília - DF - Brasil jldafranco@terra.com.br

José Augusto Drummond SQN 206, Bloco J, apto. 102 70844-000 Brasília - DF - Brasil jaldrummond@uol.com.br

Centro de Desenvolvimento Sustentável e Programa de Pós-graduação em Desenvolvimento Sustentável / Universidade de Brasília
FRANCO, José Luiz de Andrade; DRUMMOND, José Augusto. Cândido de Mello Leitão: as ciências biológicas e a valorização da natureza e da diversidade da vida. História, Ciências, Saúde - Manguinhos, Rio de Janeiro, v.14, n.4, p.1265-1290, out.-dez. 2007.

Examina o pensamento do zoólogo brasileiro Cândido de Mello Leitão (1886-1948). Explora aspectos do seu pensamento relacionados à preocupação com a valorização do conhecimento científico e da natureza em toda a sua diversidade. Destaca episódios relevantes de sua biografia pessoal e profissional, bem como analisa parte de sua produção bibliográfica, publicada entre 1935 e 1947. Mello Leitão afirmava a necessidade de um processo civilizador que reconciliasse o homem e o mundo natural, processo no qual ciência e Estado teriam responsabilidades a compartilhar, sobretudo no Brasil, país que ele considerava estar em busca de identidade nacional e de um modelo de civilização.

PALAVRAS-CHAVE: Cândido de Mello Leitão; conservação da natureza; Museu Nacional do Rio de Janeiro; história da ciência; fauna selvagem; zoogeografia.

FRANCO, José Luiz de Andrade; DRUMMOND, José Augusto. Cândido de Mello Leitão: the biological sciences and the valorization of nature and diversity of life .

História, Ciências, Saúde - Manguinhos, Rio de Janeiro, v.14, n.4, p.1265-1290, Oct.-Dec. 2007.

This exploration of the thought of Brazilian zoologist Cândido de Mello Leitão (1886-1948) concentrates on his concern with valuing scientific knowledge and nature in all its diversity. The article highlights relevant episodes from his personal and professional life and analyzes part of his bibliographic production, published between 1935 and 1947. Mello Leitão asserted the need for a civilizing process that could reconcile man and the natural world. Science and the State should share responsibilities in this endeavor, especially in Brazil, which Mello Leitão felt was searching for a national identity and a model of civilization.

KEYWORDS: Cândido de Mello Leitão; conservation; Museu Nacional do Rio de Janeiro; history of science; wild fauna; zoogeography. 
$\mathrm{O}$ presente texto resume os resultados da pesquisa de José Luiz de Andrade Franco (2002, cap.3) sobre o naturalista Cândido de Mello Leitão (1886-1948). Explora aspectos do pensamento do naturalista sobre a valorização do conhecimento científico e da natureza. Ressalta episódios relevantes de sua biografia pessoal e profissional e focaliza aspectos da sua produção bibliográfica publicada entre 1935 e 1947, sobretudo aquela que trata diretamente da importância da atividade científica no Brasil e da sua relação com o conhecimento e o amor pela natureza.

A trajetória e a produção de Mello Leitão evidenciam uma intenção de unir razão e sentimento, de resgatar, por meio da pesquisa científica e do conhecimento, a proximidade dos humanos com a natureza, ajudando a restabelecer os vínculos entre humanos e o mundo natural. A sua obra mostrou também como a biologia se constituiu em fonte de conhecimentos sobre o Brasil e como ela poderia orientar a transformação de uma relação imediatista e predatória com a natureza em uma outra, baseada no cuidado e desvelamento de seus segredos.

Selecionamos, entre a extensa obra de Mello Leitão, quatro livros para análise: A biologia no Brasil (Leitão, 1937a), A vida maravilhosa dos animais (Leitão, 1935), A vida na selva (Leitão, 1940) e Zoogeografia do Brasil (Leitão, 1937b, 1947).

\section{Dados biográficos}

O zoólogo Cândido de Mello Leitão foi professor do Museu Nacional do Rio de Janeiro (MNRJ). Ele pertencia a um grupo - razoavelmente bem organizado e constituído, em sua maioria, por cientistas, intelectuais e funcionários públicos - que pretendia fazer o Estado implementar políticas relacionadas à conservação do patrimônio natural brasileiro. A maneira como esse grupo se inseriu no contexto político-intelectual da época e o seu relativo sucesso estiveram associados ao fato de ter conectado as suas preocupações sobre a proteção da natureza com a questão da identidade nacional.

O grupo empenhou-se em articular propostas relacionadas ao conceito de proteção à natureza com um projeto político mais amplo, de cunho nacionalista. Data dessa época a edição da primeira geração de leis brasileiras de proteção da natureza - o Código Florestal, o Código de Caça e Pesca, o Código de Águas, o Código de Minas e o Código de Fiscalização das Expedições Artísticas e Científicas, instituídos entre maio de 1933 e outubro de 1934. Além disso, a própria Constituição de 1934 encarregava os governos central e estaduais de proteger as "belezas naturais" e os "monumentos de valor histórico ou artístico". Pouco depois foram criados os primeiros parques nacionais brasileiros: Itatiaia, em 1937, e Serra dos Órgãos e Iguaçu, ambos em 1939 (Drummond, 1999). 


\footnotetext{
${ }^{1}$ A respeito do

desenvolvimento do conhecimento científico sobre o mundo natural e do surgimento de uma preocupação com a sua conservação, ver Thomas, 1996;

McCormick, 1992; Worster, 1994; Nash, 1982, 1989; Pádua, 2002; Acot, 1990; e Alphandéry, Bitoun, Dupont, 1992.
}

O esforço de elaboração intelectual desse grupo se fundamentava na apropriação de tradições de pensamento que combinavam o conhecimento científico do mundo natural com a noção de que tal mundo devia ser conservado por motivos econômicos e estéticos. ${ }^{1}$

No Brasil, esse tipo de perspectiva formou-se, sobretudo, no interior de algumas poucas instituições científicas, das quais a principal foi o MNRJ. Ao realizar pesquisas nos campos da história natural, biologia e antropologia, cientistas e professores dessa instituição logo despertaram para o problema da destruição do patrimônio natural pelas ações humanas. Vários deles dedicaramse ao ativismo e à formulação de um pensamento focalizados na proteção da natureza. Entre eles encontram-se o próprio Cândido de Mello Leitão, Edgar Roquette-Pinto e seu filho Paulo RoquettePinto, Bertha Lutz, Heloísa Alberto Torres, Armando Magalhães Corrêa e Alberto José Sampaio. Frederico Carlos Hoehne, que teve em São Paulo atuação destacada em favor da proteção da natureza, também começou a sua carreira como botânico e taxonomista no Museu (Franco, 2002).

Esses intelectuais desempenharam, também, papel importante junto a grupos cívicos voltados para a questão da proteção à natureza. Destacavam-se associações como o Centro Excursionista Brasileiro, cujos guias foram credenciados como guardas florestais; a Federação Brasileira para o Progresso Feminino, que tinha a bióloga Bertha Lutz como uma de suas líderes; a Sociedade de Amigos de Alberto Torres (Armando Magalhães Corrêa e Alberto José Sampaio estavam entre os seus fundadores); a Sociedade Geográfica do Rio de Janeiro; a Sociedade de Amigos das Árvores (fundada em 1931 por Alberto José Sampaio) e a Sociedade dos Amigos do Museu Nacional (constituída por funcionários da instituição). Em São Paulo, Frederico Carlos Hoehne organizou a Sociedade de Amigos da Flora Brasílica, que incluía em seu quadro de sócios fundadores, além de cientistas e funcionários públicos, horticultores e fazendeiros inovadores (Dean, 1996). Além disso, os cientistas do MNRJ tiveram uma participação destacada como organizadores e participantes da Primeira Conferência Brasileira de Proteção à Natureza, realizada em 1934, no Rio de Janeiro (Franco, 2002; jan. 2002).

Mello Leitão empenhou-se também no desenvolvimento da pesquisa em biologia. Além de estudos sobre aracnídeos, sua especialidade, interessou-se por ecologia, distribuição geográfica e conformação dos hábitats dos animais, bem como do comportamento destes. Erudito, buscou historiar e sistematizar todo o saber biológico produzido até então sobre o Brasil (Duarte, 2005; jul.-dez. 2000).

Natural de Campina Grande, na Paraíba, Mello Leitão iniciou seus estudos no Grêmio de Instrução Campinagrandense. Formou-se em medicina, em 1909, pela Faculdade de Medicina do Rio de Janeiro. 
$2 \mathrm{O}$ exemplo mais célebre é o de Augusto Ruschi, formado no MNRJ que fundou e dirigiu um museu batizado em homenagem a Mello Leitão (Museu de Biologia Professor Mello Leitão), em Santa Teresa, no Espírito Santo.
Exerceu a pediatria e foi livre-docente das cadeiras de Clínica Médica Pediátrica e Higiene Infantil da Faculdade de Medicina da Universidade do Rio de Janeiro. Lecionou também na Faculdade de Medicina de Belo Horizonte, em Minas Gerais. A paixão pela zoologia, no entanto, foi maior, e em 1913 prestou concurso público de professor de Zoologia Geral na Escola Superior de Agricultura e Medicina Veterinária do Rio de Janeiro. Em poucos anos projetouse na área, tornando-se professor de biologia na Escola Normal (atual Instituto Superior de Educação do Rio de Janeiro) e no MNRJ.

Mello Leitão participou de associações científicas, tendo sido vicepresidente (1937-1939) e presidente (1943-1945) da Academia Brasileira de Ciências. Publicou regularmente em periódicos científicos como Anais da Academia Brasileira de Ciências, Revista Brasileira de Geografia, Brotéria (Portugal), Revista Brasileira de Biologia, Revista do Museu Paulista, Arquivos do Museu Nacional e Arquivos do Instituto Biológico e escreveu vários livros. Também atuou junto ao Ministério da Agricultura, nos anos 1930 e 1940, como integrante e presidente do Conselho Nacional de Caça e Pesca e consultor para assuntos de zoogeografia do Conselho Nacional de Geografia.

Era amigo pessoal de Fernando Azevedo, o editor da renomada Coleção Brasiliana, da Companhia Editora Nacional, o que lhe facilitou a publicação de muitos de seus livros (Duarte, 2005; jul.-dez. 2000). Foi também amigo de Edgar Roquette-Pinto, diretor do MNRJ entre 1926 e 1935 e um dos pioneiros da radiodifusão no Brasil. Recorreu regularmente a programas de rádio para difundir seus conhecimentos biológicos. Suas relações pessoais e os cargos que ocupou dão uma medida das possibilidades que teve para exercer influência. Como professor, Mello Leitão participou da formação de novos cientistas que ajudaram a construir os padrões da pesquisa científica brasileira nos campos da zoologia e da botânica. ${ }^{2}$

\section{Emergência da ciência da biologia no Brasil}

Edgar Roquette-Pinto (1884-1954), outro interessado na proteção da natureza, comentou, em seu prefácio ao livro $A$ biologia no Brasil (Leitão, 1937a), a importância daquele texto que mostrava o surgimento da história natural no Brasil. Tal obra, segundo ele, só podia ter sido composta por um "naturalista de raça", capaz de apontar "com segurança todas as dificuldades que a ciência veio encontrando para conseguir ambiente, neste país; mas também deixa bem marcado o admirável surto que ela conseguiu nos últimos cinqüenta anos" (p.10). Para os cientistas do MNRJ, o conhecimento científico tinha relação estreita com o amor à natureza. Eles queriam resgatar, por meio de pesquisa e conhecimento, a proximidade com os elementos da natureza, ajudando a restabelecer os vínculos entre os humanos e o mundo natural. Segundo Roquette- 
Pinto, a obra de Mello Leitão mostrava como a biologia era uma fonte de conhecimentos sobre o Brasil e poderia nos ajudar a superar a relação de imediatismo predatório com a natureza, para nos fazer alcançar uma outra relação, baseada no cuidado e desve-lamento dos segredos dela.

A biologia no Brasil inicia mostrando a influência dos grandes descobrimentos da expansão européia sobre a história natural no século XVI. Para Mello Leitão, foi então que se aguçou mais a curiosidade européia em torno do mundo natural. Ele atribuía papel decisivo a dois acontecimentos: a invenção da imprensa de caracteres móveis e as viagens de Vasco da Gama e Colombo. A descoberta e exploração de novas terras e as notícias sobre uma natureza até então desconhecida para os europeus estimularam numerosos estudos sobre o mundo natural (Leitão, 1937a, p.19).

Mello Leitão observava que, infelizmente, Portugal fora refratário aos conhecimentos especulativos. Pragmaticamente, demonstrou pouco interesse nos aspectos maravilhosos da natureza no Novo Mundo, "nascendo o Brasil quando as novas terras iam dar novo rumo às ciências, conquistado em nome de um reino onde mal tinham encontrado guarida às organizações universitárias, era lógico que as riquezas imensas de sua fauna e sua flora não se refletissem nas obras da época" (Leitão, 1937a, p.20). Referia-se o naturalista ao atraso de Portugal na montagem de um sistema moderno de ensino universitário. De modo geral, porém, houvera, naquele momento, "entre os relatos dos navegadores e cronistas e os livros de zoologia e botânica uma tal semelhança, que força é considerá-los, se não na história geral da biologia, na particular das novas regiões" (p.20-21).

Mello Leitão resume os conhecimentos biológicos no Quinhentos à criação de novas formas de classificar plantas e animais e ao surgimento de forte curiosidade sobre anatomia e fisiologia. Apesar dos progressos, esses conhecimentos eram bastante imprecisos: “ $\mathrm{O}$ simples relato de viajantes era, por isso mesmo, mais precioso que os longos comentários sobre clássicos gregos e romanos e, tratando do conhecimento da vida no Brasil, é justo que se dê, nesse século XVI, guarida aos cronistas" (Leitão, 1937a, p.29). Entre os cronistas eram citados Pero de Magalhães Gandavo, André Thevet, Jean de Léry, Gabriel Soares de Sousa, José de Anchieta e Fernão Cardim, cujas narrativas descreviam plantas, frutos e animais selvagens. Mello Leitão destacava a pouca atenção dispensada pelas autoridades portuguesas a essas descrições.

Para o naturalista, o século XVII fora dos mais notáveis e brilhantes na história da biologia:

Esse século que viu Descartes, Spinoza, Leibniz, Newton, foi também o século de Borelli, Malpighi, Leeuwenhock, Swammerdam, 
de Ray. O vitrum pulicare dos Janssen, de simples instrumento de curiosidade e divertimento, ia, aperfeiçoado, tornar-se o microscópio que abria um mundo maravilhoso e inexplorado à curiosidade dos biólogos; o modesto perspicillum que já permitira a Harvey o estudo da circulação do sangue dos insetos, o megascópio de que se utilizava para procurar o bicho-do-pé, transformavam-se nos aparelhos com que Leeuwenhock via os Infusórios, com que Malpighi e Grew, independentemente, descobriam a célula. (Leitão, 1937a, p.63-64)

A Península Ibérica continuou alheia às especulações científicas. Foram principalmente franceses (Claude d'Abbéville e Yves d'Évreux) e holandeses (William Piso e Georg Marcgrav) que estudaram a fauna e a flora do Brasil. Mello Leitão creditava aos holandeses a 'obra mais notável' sobre a natureza do país em todo o período colonial. Eram mencionados ainda Acuña, por seu Novo descobrimento do grande rio Amazonas, e Brandonio (Ambrósio Fernandes Brandão - segundo Capistrano de Abreu), pelos Diálogos das grandezas do Brasil.

O século XVIII, do Iluminismo, segundo Mello Leitão, marcou a biologia de dois modos. Primeiro, com o sistema de nomenclatura binária criado pelo sueco Carlos Linneu (1707-1778), fundamental para o moderno sistema de classificação de plantas e animais. Segundo, por ter vindo a público o tratado de biologia descritiva Histoire naturelle, de Buffon (Georges-Louis Leclerc, 1707-1787). Mello Leitão mencionava os pesquisadores importantes daquele século para a biologia, De Geer, Fabricius, Réaumur, Haller, Bonnet, Wolff, Koeulreuter e Pallas, e os chamados filósofos da natureza, Herder, Fichte, Schelling e Goethe.

No mesmo século XVIII, "tão repleto de inovações no campo das ciências", o Brasil fora como "um deserto". Mello Leitão lamentava o desinteresse da metrópole por conhecer a exuberante natureza da colônia. As poucas iniciativas haviam sido efêmeras, porém surgiram, em Portugal e no Brasil, as academias literárias, resultantes de ímpetos de curiosidade científica, que facilitaram a circulação e o debate de idéias. Algumas personalidades portuguesas se destacaram, sobretudo Alexandre Rodrigues Ferreira (1756-1815), líder da primeira grande expedição propriamente científica a terras brasileiras, estimulada pela Coroa portuguesa; frei José Mariano da Conceição Velloso (1742-1811); Manoel Arruda da Câmara (1752-1810); além de figuras menores como José de Sá Bittencourt, Balthazar da Silva Lisboa, Diogo de Toledo Lara e Ordonhes e João da Silva Feijó.

Para Mello Leitão, a busca pelo conhecimento da natureza brasileira - empreendida em sua maior parte, até o fim do século XIX, por não-brasileiros e por não-portugueses - foi, paradoxalmente, um elemento fundamental para a afirmação da identidade nacio- 
nal. Em A biologia no Brasil, essa preocupação aparece nas análises que estabelecem um vínculo entre investimentos na ciência, valorização da natureza e consciência da nacionalidade.

Somente no século XIX o Brasil tornar-se-ia, na opinião do naturalista, um país independente, quando "a biologia toma novos rumos, abrem-se novas rotas às pesquisas e surgem novas ciências, apenas pressentidas no século precedente" (Leitão, 1937a, p.115116). Defendia o autor que a virada do século XVIII para o XIX trouxera quatro grandes criadores de ciências: Humboldt, Lamarck, Cuvier e Bichat. Ainda na primeira metade do século XIX, outras novidades surgiram nas ciências biológicas, graças aos estudos de Von Baer, Magendie, Flourens, Bernard, Schleiden, Schwann, Leuckart, De Candolle e Endlicher. Foi também no mesmo período que se multiplicaram, na Europa, as sociedades científicas e que começaram a ser publicadas importantes revistas científicas especializadas, permitindo o aprofundamento e intercâmbio de estudos em domínios cada vez mais específicos. Mello Leitão (1937a, p.119-120) observava que:

Coincide com esse magnífico desabrochar das ciências e resulta da sistematização de todos os conhecimentos, o interesse pelas regiões exóticas, a sedução da natureza tropical, interesse e sedução que vão formar uma das características do Romantismo, interesse e sedução que chegam até as esferas governamentais, aprestando-se as viagens de exploração científica. A vinda de D. João VI com a conseqüente abertura dos portos do Brasil; a trégua mais dilatada às constantes guerras em que se estraçalham as nações de Europa; a curiosidade por esse mundo tanto tempo segregado das vistas de estranhos e do qual viajantes clandes-tinos diziam maravilhas boas e más; a coroa deste longínquo e distante império posta na fronte de uma princesa austríaca: eis outros tantos motivos do estudo de nosso país.

$\mathrm{O}$ autor mencionava alguns dos numerosos viajantes naturalistas que estudaram o Brasil durante o século XIX, nenhum deles português ou brasileiro: W.L. von Eschwege; Koster; o príncipe Maximiliano de Wied; G.W. Freyreiss; Sellow; Swainson; Waterton; Auguste de Saint-Hilaire; J. Emmanuel Pohl; Spix; Martius; Natterer; Georg von Langsdorff; Alcide D. d'Orbigny; Castelnau; Van Beneden; Longchamps; Von Volxen; Charles Darwin; Alfred Russel Wallace; Henry Walter Bates; Louis Agassiz; e Spruce. Além desses, o autor citava outros estudiosos estrangeiros - igualmente não-portugueses e não-brasileiros - que passaram no Brasil a maior parte de suas vidas de biólogos: Lund; Hermann Burmeister; Emanuel Liais; Fritz Miller; Herman von Ihering; Emílio Goeldi; Wucherer; Paterson; e Louis Couty. Na opinião do autor, devíamos a esses naturalistas e viajantes estrangeiros o início do conhe- 
${ }^{3}$ Sobre a formação dos museus brasileiros, ver Lopes, 1997.
${ }^{4}$ Sobre a história do Museu Paraense Emílio Goeldi, ver Faulhaber, Toledo, 2001; e Maio, Sanjad, Drummond, 2005 cimento mais sistematizado de geologia, flora, fauna e mesmo etnologia do Brasil, e foi a partir desses fundamentos que se erigiu uma tradição brasileira de pensamento focalizada na natureza e que começaram a surgir instituições científicas.

Mello Leitão atribuía aos museus papel fundamental no desenvolvimento do conhecimento científico no Brasil. $\mathrm{O}$ autor dedicou um capítulo inteiro de $A$ biologia no Brasil à análise da criação do MNRJ, do Museu Paraense (hoje Museu Paraense Emílio Goeldi) e do Museu Paulista. ${ }^{3}$ Mostrava as dificuldades que essas instituições enfrentaram para alcançar condições mínimas de funcionamento.

O MNRJ, por exemplo, criado em 1818, tivera o apoio de José Bonifácio, mas assim mesmo o poder público deixara a instituição, desde o seu início, "quase ao abandono, um quase abandono que perdura há 120 anos" (Leitão, 1937a, p.170). O Museu progredira quase exclusivamente graças aos esforços dos cientistas a ele dedicados: frei Custódio Alves Serrão, Francisco Freire Alemão, Ladislau de Sousa Neto, João Batista de Lacerda, Arthur Neiva e Edgar Roquette-Pinto, entre outros. A gestão de Ladislau Neto (1874-1892) era elogiada por Mello Leitão, por várias causas: oferta de cursos públicos e gratuitos; o início da publicação da revista Arquivos do Museu Nacional; a publicação integral da Flora Fluminense, de Conceição Velloso; a organização da Exposição Antropológica; a transferência para a sede definitiva, na Quinta da Boa Vista. Daí em diante, segundo o autor, mesmo sem apoio dos sucessivos governos, "procurou-se [no MNRJ] difundir o mais possível o amor pela História Natural": cresceu o quadro de colaboradores, começou a ser editado em 1923, na gestão de Arthur Neiva, o Boletim do Museu Nacional; muitas excursões de campo foram realizadas, laboratórios foram montados e cursos foram organizados (p.188).

O Museu Paraense, por sua vez, instalado em 1867 na capital paraense, ganhara impulso com a chegada de Emílio Goeldi (18591917), zoólogo suíço convidado pelo governo do Pará para reorganizar a instituição. Goeldi fora sucedido por seus auxiliares, o botânico Jacques Huber e a zoóloga Emília Snethlage, e no período entre 1891 e 1914, já com o nome Goeldi, o museu organizara excursões, montara um jardim zoológico e um horto botânico, estabelecera estações de pesquisa, publicara o seu Boletim e realizara pesquisas nos campos da botânica, zoologia, geologia e etnografia. Seguira-se um período de decadência e abandono, até que, em 1931, rebatizado de Museu Paraense Emílio Goeldi e sob a direção de Carlos Estevão de Oliveira, fora reanimado, voltando até mesmo a publicar o Boletim em 1933. ${ }^{4}$ Para Mello Leitão, o esforço pessoal dos cientistas compensava uma vez mais o descaso do Estado com a ciência.

O caso do Museu Paulista não era diferente. Criado pelo governo do estado de São Paulo, em 1891, sob a denominação de 
Museu Sertório, fora dirigido primeiramente pelo engenheiro e botânico sueco Alberto Loefgren (1854-1918), que se empenhara na sua criação. Já sob a direção do zoólogo e botânico alemão Herman von Ihering (1850-1930) passara a chamar-se Museu Paulista, em 1894. Foi inaugurado oficialmente um ano depois, quando também iniciou-se a publicação da Revista do Museu Paulista.

Fica evidente, no texto de Mello Leitão, que esses poucos museus não receberam a devida atenção dos governos. Acrescente-se que faltavam também no Brasil as universidades (com os seus departamentos de história natural), cuja criação fora notoriamente tardia. Mello Leitão reconhecia que, mesmo assim, a botânica e a zoologia progrediram no Brasil, sobretudo no século XX. Com a botânica "nascem os nossos estudos biológicos e recebem os primeiros nomes brasileiros a atenção de sábios de outras terras" (Leitão, 1937a, p.209-210). Foi o valor econômico de certas plantas que, segundo Mello Leitão, contribuiu para o maior desenvolvimento da botânica. Ainda no período colonial, tomaram-se algumas medidas (por Rodrigo de Sousa Coutinho, conde de Linhares, ministro do futuro d. João VI) para disciplinar o uso dos recursos naturais no Brasil, o que levou à criação de jardins botânicos e hortos reais. Houve, também, tentativas de regulamentar os cortes das matas.

Fruto dessas preocupações, o Jardim Botânico do Rio de Janeiro, criado em 1808, tornou-se uma das mais importantes instituições de estudos botânicos no país. Para Mello Leitão, tal mérito cabia ao botânico e frei Leandro do Sacramento, diretor de 1822 a 1829. Posteriormente, entre 1890 e 1909, João Barbosa Rodrigues, considerado por Mello Leitão um dos mais notáveis botânicos brasileiros, assumira a direção da instituição, modernizando-a e consolidando a sua missão de pesquisa e produção científica.

Papel importante tiveram também a Academia Médico-cirúrgica do Rio de Janeiro e a Academia Militar, onde se criaram cadeiras para o ensino da botânica. Nelas lecionaram muitos expoentes, entre os quais frei Custódio Alves Serrão, frei Leandro do Sacramento, Francisco Freire Alemão, Saldanha da Gama e Joaquim Monteiro Caminhoá. Mello Leitão registrava com satisfação a emergência de quadros de botânicos brasileiros e estrangeiros residentes no Brasil, que sucediam as gerações de viajantes e naturalistas estrangeiros que excursionaram e pesquisaram no Brasil:

A flora magnífica do Brasil continuava a tentar os filhos doutras terras como aos que neste país se dedicavam às ciências naturais ... E por isso vemos, misturados e entretecidos, nomes brasileiros e estranhos na teoria esplendida de botânicos que enchem os últimos sessenta anos de ciência brasileira. E se por um momento podia escrever um von Ihering que 'com Barbosa Rodrigues desapareceu o último representante da plêiade de excelentes 
botânicos do Rio de Janeiro', logo a cadeia se refaz e Alberto Sampaio, A. Ducke, A. Loefgren, Kuhlman continuam na Capital do país a série notável, enquanto Hoehne em S. Paulo e Álvaro da Silveira em Minas Gerais são seus dignos êmulos. (Leitão, 1937a, p.209-210)

Entre os grandes nomes da botânica no Brasil naquela fase mais recente, Mello Leitão citava ainda os brasileiros Ladislau Neto, Nicolau Moreira, Leônidas Damásio, Henrique de Mello Barreto, Pio Correa, Edmundo Navarro de Andrade e Octávio Vecchi e os estrangeiros André Regnel, W. Schwacke, A. Glaziou, E. Warming, E. Liais, E. Ule, P. Dusen, T. Peckolt, C.A. Lindman, J. Huber e A. Brade. O naturalista considerava haver apenas quatro grandes centros de estudo da botânica no país, no início do século XX: o Jardim Botânico do Rio de Janeiro, o MNRJ, o Instituto Butantan e o Jardim Botânico de Minas Gerais.

Mello Leitão não reputava à zoologia do século XIX, no Brasil, o mesmo brilho da botânica. Quase tudo o que se escrevera então sobre a nossa fauna tinha sido assinado por estrangeiros: Spix, Maximiliano de Wied, Burmeister, Agassiz, Bates, Fritz Mueller, Herman von Thering, Goeldi, Liais, Pelzaln, Perty, Winge, Steindachner e Keyserling. Pouco havia sido escrito por brasileiros, e "essa escassa contribuição é, com exceção dos trabalhos de Silva Maia, devida a simples amadores de zoologia, ora especializados em botânica, como Freire Alemão, ora em mineralogia, como Burlamaqui, ou simples literatos, como José Veríssimo" (Leitão, 1937a, p.235-236).

Ainda no último decênio do século XIX, com o aparecimento da Revista do Museu Paulista e do Boletim do Museu Paraense, publicaram-se importantes trabalhos zoológicos. Na virada do século XIX para o XX, os estudos zoológicos ganharam maior impulso, com o Instituto Oswaldo Cruz investindo em estudos zoológicos. Para Mello Leitão, a partir de 1905 acelerara-se de tal maneira o ritmo das publicações zoológicas, que ficou difícil acompanhar a produção dos nossos zoólogos. Entre os estrangeiros que aqui trabalhavam, além dos conhecidos Goeldi e Ihering, destacavam-se Emília Snethlage, Hempel, Townsend, Borgmeyer, Luederwaldt, Melzer, Vellard e Schirch. Entre os brasileiros, além de Adolpho Lutz e Oswaldo Cruz, considerados os maiores animadores de nossa zoologia, são citados Carlos Chagas, Paulo Carini, João Florêncio Gomes, Arthur Neiva, Costa Lima, Lauro Travassos, Afrânio Amaral, Fabio Werneck, Miranda Ribeiro, Olivério de Oliveira Pinto, Vital Brasil, Rodolfo von Ihering e Bertha Lutz.

Mello Leitão tratou também do desenvolvimento da antropologia, da anatomia e da fisiologia, compreendidas como subdivisões da biologia. Com relação à primeira, entendia que ela caracteriza os grupos humanos existentes no país, especialmente os indígenas. O MNRJ era a principal instituição envolvida. Mello 
Leitão reviu as contribuições de viajantes naturalistas como Alexandre Rodrigues Ferreira e Auguste de Saint-Hilaire, nos séculos XVIII e XIX, e os trabalhos posteriores de Carlos von den Stein, Paulo Ehrenreich, do casal Coudreau, de Koch-Grünberg e Max Schmidt. Eram citados como fundadores da antropologia brasileira os trabalhos de Couto de Magalhães, Batista de Lacerda, Barbosa Rodrigues e, sobretudo, Peter Lund e Edgar Roquette-Pinto. No que concerne à anatomia, Mello Leitão destacava Benjamin Batista, Fróes da Fonseca, Alfonso Bovero e Paulo Sawaya; na fisiologia, mencionava os irmãos Álvaro e Miguel Osório de Almeida, Tales Martins, Couto e Silva e Paulo Galvão. Assim, nos princípios do século XX já havia um número expressivo de brasileiros compondo uma comunidade científica ligada às ciências biológicas.

No último capítulo, Mello Leitão estudava a relação entre a 'pungente' natureza do país e a solução de alguns dos 'grandes' problemas biológicos. Referia-se sobretudo aos problemas ligados ao que considerava o acontecimento máximo da biologia no século XIX: “a publicação do livro de Darwin - $A$ origem das espécies, que vinha abrir em todos os campos da biologia novos caminhos à investigação, acender as mais vivas polêmicas e, passado o exagero dos primeiros entusiasmos, servir como ótima hipótese de trabalho" (Leitão, 1937a, p.303). As idéias desenvolvidas nesse livro, segundo Mello Leitão, haviam nascido do contato de Darwin com a fauna sul-americana, que o impressionou pela distribuição e pelas relações geológicas entre os seus integrantes atuais e passados. Wallace, que chegou a conclusões próximas às de Darwin sobre a origem das espécies, "sentira igualmente a influência de nossa natureza, tendo vivido na Amazônia, onde seu espírito de filósofo e de poeta plenamente desabrochou" (p.305). Bates, Fritz Mueller e Peter Lund, que conheceram a natureza do Brasil, também desenvolveram teorias em favor da hipótese darwiniana. Mello Leitão argumentava dessa forma o grande valor que tiveram as formas de vida encontradas no Brasil para a evolução do conhecimento científico global.

\section{As maravilhas da vida}

A vida maravilhosa dos animais e A vida na selva, publicados respectivamente em 1935 e 1940, reúnem conferências de Mello Leitão sobre zoologia. Divulgaram as suas idéias para um público nãoespecializado e revelaram aspectos importantes do seu pensamento sobre a organização do mundo natural.

Em $A$ vida maravilhosa dos animais, Mello Leitão interpretava as formas de organização dos seres vivos com base no comportamento deles. Via a vida como um processo evolutivo, embora discordasse do papel determinante, atribuído por Darwin, à competição entre as espécies e à seleção natural. Para ele, o aspecto funda- 
mental era a cooperação: a sobrevivência dos seres dependia, em grande parte, da sua capacidade de articular vínculos cooperativos. Assim, se observássemos as formas de organização social dos animais, encontraríamos "os mesmos tipos que nos apresenta, em sua evolução, a história da humanidade" (Leitão, 1935, p.15). Havia um contraste vivo entre "o egoísmo feroz, a indiferença completa, o individualismo intransigente dos animais aquáticos e a tendência, cada vez mais notável, à vida social dos terrestres" (p.15). Entendia o autor que o comportamento animal se estruturava em torno de dois eixos, um agressivo e individualista, predominante na fauna aquática, e outro cooperativo ou social, mais comum entre os seres terrestres, resultando um estado de simbiose característico dos equilíbrios encontrados na natureza.

Após comentar a vida social de diversos grupos de artrópodes e vertebrados, Mello Leitão deleitava-se com as maravilhas do mundo animal, expostas em capítulos que apresentam as "obras de engenharia", as "relações de amizade e comensalidade" entre espécies distintas e o "canto e a dança nos animais". Procurava mostrar que o homem encontrou na natureza as soluções para os problemas surgidos na vida em sociedade. Ao tratar da questão da amizade e comensalidade entre os animais, Mello Leitão explicava que "a natureza apareceu sempre ao homem como incessante combate, como luta sem tréguas" (Leitão, 1935, p.21). No entanto, se observadas mais de perto as relações entre os seres vivos, perceberíamos "que a natureza é sempre uma grande harmonia, onde a mútua dependência, o auxílio, diria mesmo a amizade, é regra geral" (p.63).

A observação atenta do mundo natural revelaria, segundo o autor, o equilíbrio orgânico a envolver todos os seres. Tensões e conflitos se resolveriam na conformação geral do hábitat. Dessa forma, ao estudarmos as relações entre os seres que vivem na mesma região, "podemos encontrar todos os graus, desde a mais completa indiferença até a mais estreita dependência, seja em benefício de um e dano mais ou menos grave do outro - parasitismo, predatismo - seja em benefício cada vez mais manifesto de ambos mutualismo, simbiose" (Leitão, 1935, p.63).

A atenção para o equilíbrio entre manifestações de competição e cooperação reaparece em capítulo devotado às "plantas que devoram" e às que "abrigam" os animais. Mello Leitão ressaltava que as plantas sustentam todas as formas de vida animal, mas que certos animais atuam na polinização e propagação das sementes. Havia entre os dois reinos, portanto, uma imbricada dependência.

O 'maravilhamento' frente ao processo evolutivo é a tônica dos capítulos dedicados à relação entre as fantasias humanas sobre animais monstruosos e aqueles presentes de fato na natureza; à vida das formigas, aos seus engenhos e à sua vida social; e à vida das aranhas (a principal especialidade de Mello Leitão). 
Os três últimos capítulos introduzem o debate sobre visões de natureza. No primeiro, Mello Leitão discute os 'grandes marcos' da zoologia: Aristóteles, pioneiro na classificação dos animais; Cuvier, criador da anatomia comparada; e Darwin, formulador da teoria da evolução das espécies. Para Mello Leitão (1935), a hipótese de Darwin era brilhante e fecunda, embora fosse importante notar como "o darwinismo aparecia como aliado do liberalismo, porque se apresentava elevando a doutrina da livre competição, uma das pedras angulares do progresso, ao nível de lei natural" e como "os povos imperialistas fizeram da 'sobrevivência do mais forte' princípio básico de sua política e pretexto para domínio senão extermínio das nações mais fracas" (p.226). Ele questionava, no evolu-cionismo, a ênfase dada à competição e à prevalência dos mais fortes. Discordava do uso das explicações da biologia para justificar práticas sociais que considerava 'imperialistas'. Entendia também que, em muitos aspectos, as hipóteses de Darwin careciam de confirmação ou mesmo de reformulação. Não negava o princípio da evolução, "uma das mais férteis hipóteses de trabalho" (p.227).

Para Mello Leitão, a teoria de Darwin compunha-se de duas partes. De um lado havia a teoria da evolução, a qual sustentava que as diferentes formas de vida desenvolveram-se gradualmente a partir de uma origem comum, fato comprovado pelas evidências fósseis; de outro estava a seleção das populações e dos indivíduos, resultante de uma luta pela existência e levando à sobrevivência dos mais aptos. Nesta última parte, Darwin procurava explicar as causas da evolução, embora faltassem maiores comprovações empíricas. Para Mello Leitão, foi Gregor Mendel, criador dos fundamentos da genética moderna, que possibilitou estudos mais acurados e com maior aporte científico sobre os mecanismos da evolução das espécies.

O naturalista estava certo ao atribuir aos estudos no campo da genética a via pela qual se poderia chegar a uma explicação dos mecanismos atuantes no processo de especiação. No entanto, sua resistência e mesmo miopia em relação à seleção natural, mais tarde comprovada pela própria genética e pelos estudos de populações, deve-se em parte à associação que ele fazia entre as facetas da teoria darwiniana e a competição legitimada pela ideologia liberal. Isso foi muitas vezes reforçado por argumentos transpostos mecanicamente do campo da biologia para a explicação da sociedade, como no caso do darwinismo social, transposição de que o próprio

5 A esse respeito, ver Gould, 1999; Mayr, 1998; e Desmond, Moore, 2000.
Darwin suspeitava. ${ }^{5}$ Além do mais, Darwin era enfático ao insistir em que a mudança orgânica conduz apenas a uma maior adaptação dos organismos ao seu meio ambiente, e não a um ideal abstrato de progresso. Isto torna sem sentido o uso de termos como 'superior' e 'inferior' e a noção de um vínculo necessário entre evolução e progresso. Assim, Mello Leitão errou ao responsabilizar Darwin 
pelas apropriações de sua teoria por parte de determinadas correntes da filosofia e das ciências sociais, bem como de ideologias políticas. E acabou por se enredar em um jogo de projeções que confundia suas análises sobre o desenvolvimento da ciência com a sua própria ideologia política nacionalista e organicista.

Mello Leitão não estava sozinho na negação da seleção natural, ponto de vista firmemente estabelecido entre os cientistas do MNRJ (Duarte, 2005). O princípio da seleção natural foi rejeitado com veemência também nos meios científicos europeu e norte-americano durante as três primeiras décadas do século XX. Foi só a chamada síntese evolucionista, ocorrida entre 1936 e 1947, que articulou os avanços da genética mendeliana com os mecanismos de explicação da seleção natural, reabilitando-a como mecanismo fundamental de explicação do processo evolutivo (Mayr, 1998).

De todo modo, para Mello Leitão a biologia possibilitava desvelar os segredos de uma natureza concebida sobretudo como harmoniosa. O desenvolvimento da biologia implicava uma valorização de seu objeto, os seres vivos. O penúltimo capítulo de $A$ vida maravilhosa dos animais trata da relação entre a fauna brasileira e a produção científica dos naturalistas viajantes, indicando os horizontes abertos ao conhecimento pelos aspectos inusitados da interação da vida no Novo Mundo. Assim como em A biologia no Brasil, o autor criticava o descaso com que as autoridades tratavam a pesquisa científica no país, pois "o imenso material coligido no Brasil, espalhado por vários museus exóticos, está à espera de governo bastante esclarecido que pense na riqueza desse cabedal e no que ele representa" (Leitão, 1935, p.246).

No último capítulo, o autor destacava a importância do espírito romântico para a valorização do mundo natural: "o nacionalismo, o individualismo, talvez um pouco exagerado dos românticos, levou-os à contemplação da natureza. Ensimesmando-se, emprestam à natureza um espírito capaz de vibrar acorde com as vibrações de suas almas" (Leitão, 1935, p.249). O naturalista apreciava sobretudo o lado mais ativo da sensibilidade romântica, aquele que teria inspirado os homens de ciência a se lançarem em busca do desconhecido. Para além da racionalidade técnica implícita no métier do cientista, Mello Leitão valorizava a sensibilidade estética da sua atividade e o valor estético do objeto da biologia.

\section{A vida na selva}

A vida na selva, de acordo com seu próprio autor, era a continuação de $A$ vida maravilhosa dos animais. Logo no primeiro capítulo, Mello Leitão destacava várias expressões de 'maravilhamento' dos viajantes estrangeiros diante da selva tropical, com o propósito de ilustrar a organização e complexidade de sua flora. Descrevia as 
comparações feitas pelos naturalistas estrangeiros entre as florestas tropicais e os bosques temperados, e entre as florestas tropicais da América do Sul e Central, Ásia e África. Interpretava ainda as observações sobre as complexas interações entre os diversos tipos de vegetação da rica flora das selvas tropicais e sobre as diversas formas de especialização - que permitem a adaptação a fatores como claridade, umidade, variação das estações seca e chuvosa, os diversos andares da floresta etc. Mello Leitão queria valorizar as selvas tropicais, sua riqueza e diversidade, seus mecanismos complexos de interação e adaptação, sua estética caracterizada pelo entrelaçamento das formas variadas de vida - tudo isso compondo uma genuína e pouco explorada fonte de conhecimentos cientí-ficos. Foi, portanto, um pioneiro da apreciação científica e estética das florestas tropicais úmidas, posição que levou muitas décadas para se disseminar entre cientistas estrangeiros e brasileiros.

Os quatro capítulos seguintes examinam traços da vida animal. Em um deles, sobre os 'reis das selvas', Mello Leitão descrevia o comportamento dos grandes carnívoros. Segundo ele, diferentemente dos botânicos, embevecidos, os zoólogos se sentiam desenganados no primeiro contato com a selva tropical americana, pois era difícil ver os animais (Leitão, 1940, p.43).

No capítulo que trata da "linguagem dos animais", Mello Leitão discutia os níveis e as formas de comunicação entre os animais - caranguejos, grilos, cigarras, formigas, abelhas, aranhas, peixes, aves e mamíferos. Concluía que, embora somente os homens fossem capazes de expressar por palavras raciocínios e abstrações, os animais podiam exprimir, de diversos modos (sons e gestos), necessidades, instintos e até mesmo sentimentos.

$\mathrm{O}$ 'andar superior' das selvas tropicais recebeu destaque especial em relação aos dois 'andares inferiores', merecendo um capítulo à parte, já que "um dos aspectos mais evidentes da vida nas selvas tropicais é a adaptação à vida arbórea, no alto dos ramos, onde há luz e alimento, abrigo seguro e facilidade de fuga" (Leitão, 1940, p.108). Há um capítulo sobre como os animais se guiam em seus deslocamentos. Fascinado pelo assunto, Mello Leitão abordava as peregrinações de formigas, abelhas, vespas, marimbondos, pomboscorreio, beija-flores e aves migratórias (p.167-168).

Os três últimos capítulos de $A$ vida na selva tratam da relação entre homem e natureza. O primeiro deles traça um histórico do surgimento de "parques e reservas". O autor mostra suas funções e discute suas justificativas. Inicia com assombro diante do fato de que um animal como o homem "sem garras, de dentes fracos, força muscular pouco desenvolvida, nu, de escassa agilidade e com os pés feitos para a marcha no solo, sem facilidades de trepar nas árvores, tenha vencido os outros animais, e tomado posse de toda a terra" (Leitão, 1940, p.169). O homem primitivo, porém, vivera 
${ }^{6}$ Diamond (2002) estuda as bases da distinção surgida entre povos 'produtores de alimentos' e 'povos coletores', dialogando com a literatura de história das civilizações. sobressaltado. Fragilizado perante os formidáveis carniceiros, achou na lapa o primeiro refúgio seguro; mais tarde inventou os instrumentos de defesa: machado de pedra lascada, foice de sílex, armas de arremesso.

Durante milênios o homem sobreviveu "exclusivamente do que lhe oferecia a natureza: os frutos maduros, as sementes, os animais que conseguia surpreender e matar" (Leitão, 1940, p.169-170). A domesticação de animais e plantas foi um passo fundamental na evolução da humanidade. Daí em diante, ela se disseminou pelo planeta, "aumentando cada vez mais as áreas ocupadas pelas aglomerações humanas, e as destinadas à agricultura ou às pastagens para o gado" (p.170-171). Nesse aspecto, Mello Leitão estava afinado com a produção dos historiadores das civilizações, que identificaram nesses episódios de domesticação um dos fatores cruciais para a constituição das civilizações complexas e para o surgimento de diferenças profundas entre estas e toda uma gama de sociedades mais simples, dependentes da coleta, caça e pesca e de formas rudimentares de agricultura. ${ }^{6}$

O autor notava que muitos animais, como auroques, bisões e cavalos selvagens, abundantes na Europa Central em tempos históricos, haviam desaparecido ou refugiaram-se muito ao norte, por causa da perseguição humana. Os grandes predadores, sobretudo o lobo, também sofreram perseguição durante séculos. A caça era franca - matavam-se animais de todas as espécies, não importando o tamanho ou a raridade. O desejo de matar mais caça com menor fadiga e a intenção de aclimatar espécies estrangeiras para caçadas especiais haviam levado ao estabelecimento de parques fechados:

Tais reservas de caça já eram conhecidas do antigo Egito. Lê-se em Xenofonte que Astiage, avô de Ciro, possuía um parque de caça onde o futuro rei dos persas se adestrava, perseguindo, ferindo, abatendo os animais selvagens; e Plínio refere que Fulvius Lupinus instalara um parque para os javalis e outras caças.

Além dos seus vastos territórios de caça, possuía Carlos Magno parques especiais em suas florestas, cercados de muros e que foram chamados 'Brogili'. Muitos grandes senhores estabeleceram instalações desse gênero, destinadas principalmente a animais de outras terras...

Foi sobretudo no século XVII que se fez sentir a necessidade da instalação de parques de caça, quando as condições da economia rural não mais permitiram deixar viver em liberdade a quantidade enorme de animais silvestres... (Leitão, 1940, p.172-173)

Segundo Mello Leitão, as maiores devastações da fauna ocorreram posteriormente, quando "aberta a caça a toda a gente, houve, pelo prazer da matança ou pela ambição do lucro, verdadeiras 
7 Sobre os direitos da natureza, ver Thomas, 1996; Nash, 1989; Barbosa, Drummond, 1994. hecatombes dos animais silvestres" (Leitão, 1940, p.173). Só muito tarde o homem percebeu os seus erros:

A caça dos animais insetívoros (especialmente das aves) trouxe como conseqüência a proliferação de grande número de insetos nocivos à agricultura, transformados em pragas terríveis, cujo combate pesou assustadoramente sobre o erário público. A este interesse puramente econômico veio juntar-se mais tarde o interesse científico de conservação das faunas características de cada região, formando-se aos poucos, no espírito dos homens de governo, a noção de proteção dos animais selvagens, abrigos para a fauna e conservação da flora, verdadeiros santuários da vida selvagem.

Foi uma larga campanha, iniciada em 1872 nos Estados Unidos... Desapareceram quase de todo as tapadas reais, os domínios de caça dos grandes senhores, e o homem moderno, sob a influência desse longo e ativo processo de educação empreendido por zoólogos apaixonados, se não olham ainda as aves e as feras com os olhos de S. Francisco de Assis, vêem, pelo menos, nos animais não domesticados criaturas com o mesmo direito à vida, dignas de proteção e amizade. (Leitão, 1940, p.174)

Esse pequeno trecho sintetizava as justificativas clássicas para a conservação da natureza: interesse econômico, avanço da ciência, estética (defesa do belo) e mesmo a ética, pois os animais teriam direito à vida. ${ }^{7}$ A ética desempenhava papel central para Mello Leitão, pois o desenvolvimento das sociedades humanas não podia ser encarado como um problema exclusivamente tecnocientífico; tratava-se sobretudo de uma evolução moral.

Segundo Mello Leitão, apenas quando a situação já se mostrava crítica tomaram-se medidas para garantir a existência da fauna do planeta:

Há uns seis lustros que se vem reunindo congressos e conferências de proteção da natureza, defendendo as belezas naturais contra realizações humanas interesseiras, quase sempre descuidosas da estética, e procurando impedir que o homem, cujos meios de ação e destruição se multiplicam com o progresso, rompa em proveito passageiro o equilíbrio dos três reinos da natureza. (Leitão, 1940, p.175)

Os parques nacionais e as reservas naturais eram, para Mello Leitão, fundamentais para garantir a perpetuação de espécies da flora e fauna. Ele fez um histórico desses locais, ressaltando a contribuição deles para a preservação da fauna. Observava que já "em 1831 [George] Catlin, o grande paisagista e etnólogo americano, reclamava do seu governo a constituição de um parque nacional para preservar as belezas naturais da região de Yellowstone ... Passa- 
ram-se quarenta e um anos: em 1872 o presidente Grant assinava o decreto criando o primeiro Parque Nacional do mundo, nessa mesma região de Yellowstone" (Leitão, 1940, p.176). De início, o que se pretendia era preservar a beleza paisagística - montanhas, cascatas, gêiseres e fontes termais. Para Mello Leitão, a preocupação com a proteção dos animais surgiria mais tarde, quando a "sede de lucros e o prazer de matar" (p.177) haviam quase exterminado os bisões. Em 1894, o Congresso norte-americano votara uma lei protegendo os animais de Yellowstone, o que possibilitou, em pouco tempo, o crescimento do número de bisões de quarenta para mais de mil. Exemplares excedentes foram mandados para outros parques nacionais, zoológicos e mesmo particulares, numa das primeiras manifestações de manejo de fauna. Mas não foram os bisões os únicos a encontrar ali abrigo e proteção:

Em Yellowstone ... os animais aprenderam que o homem não é mais o seu inimigo. E todos os anos acorrem a este célebre parque milhares de visitantes para contemplar, vivendo sem temor do homem, seguros de uma aliança que dispensou as assinaturas protocolares, os grandes ursos e pesados bisões, como as renas, antílopes, gamos, cargalis. Mais de duzentas espécies de aves aí vivem em paz... Os grandes ursos grizzly, tidos na conta de ferozes e traiçoeiros, aí se mostram afáveis ... vivendo numa quase camaradagem com os funcionários e visitantes... (Leitão, 1940, p.178-179)

Na época em que $A$ vida na selva foi escrita, quase todos os estados norte-americanos contavam com áreas de proteção à fauna selvagem. O Canadá também tinha tomado medidas de proteção à natureza, sobretudo após a Primeira Guerra Mundial, quando o "poético refúgio canadense de Ajawaan" (Leitão, 1940, p.183) foi transformado numa reserva especialmente destinada aos castores.

Mello Leitão considerava exemplar o Parque Nacional Paul Kruger, a mais antiga reserva africana, que surgiu em 1898 como reserva de caça e foi progressivamente ampliado até 1903 , quando a caça foi proibida. O naturalista via no turismo uma atividade econô-mica compatível com a conservação da natureza. Percebia que, ao lado das medidas para preservação da flora e fauna, era preciso viabilizar o desenvolvimento socioeconômico nas imediações das áreas protegidas. Mencionava ainda os parques nacionais do então Congo Belga e duas vastas reservas para os elefantes na então Rodésia.

Na Ásia, Mello Leitão conhecia as reservas florestais da Birmânia e o Parque Nacional de Gunong Tahan, na Malásia. Já na Nova Zelândia, o governo destinava grandes extensões de terra para parques nacionais e reservas. Estes eram a única esperança para animais como coala, gambá, ornitorrinco, dasiuro, rato-castor, vombate, as diversas espécies de cangurus, valabis, pássaros-lira e emus. 
Na América do Sul, o autor sabia da existência de quatro parques nacionais: Nahuel Huapi, na Argentina, e Itatiaia, Iguaçu e Serra dos Órgãos, no Brasil. No entanto, em sua opinião, nenhum deles correspondia plenamente à finalidade de reserva faunística, sendo simples regiões de turismo. Sobre o parque argentino notava que:

O parque Nahuel Huapi ... compreende uma das regiões mais lindas da América do Sul, com sua cadeia de lagos, seus bosques, seus picos nevados ... Não são, porém, as suas condições as mais favoráveis para uma reserva, dada a pobreza faunística dessa região e antes deve ser considerado como destinado a preservar os monumentos naturais desse maravilhoso recanto... (Leitão, 1940, p.193-194)

A perspectiva de Mello Leitão era a de uma natureza bela e harmônica, que no entanto podia ser manejada pelo homem, desde que com base em conhecimentos científicos. Era fundamental, segundo ele, prever os efeitos da ação humana sobre os equilíbrios bióticos.

Sobre os parques nacionais brasileiros, Mello Leitão afirmava:

O parque do Itatiaia é apenas pequena reserva florestal. Como reserva de nossa escassa flora alpina, não podia ser melhor escolhida a situação; quanto à fauna, porém, seu valor é quase nulo, por isso mesmo que as suas condições climáticas e ecobióticas, muito diversas do resto do Brasil, fazem dessas elevadas altitudes quase um deserto ...

O parque de Iguaçu ... poderia prestar-se, vantajosamente, à reserva e proteção do guará e da lontra, mas as construções que aí se fazem ... são de molde a apressar o desaparecimento da fauna ainda aí, por acaso, encontrada, e será um simples parque de turismo paisagista.

O chamado parque da Serra dos Órgãos, em terras de alta valorização, talvez poupe por algum tempo a flora. Quanto à fauna, será um deserto sem expressão. (Leitão, 1940, p.194)

Pessimista, Mello Leitão observava que os parques nacionais brasileiros não recebiam apoio das autoridades: não se investia o suficiente para a criação e manutenção de uma estrutura adequada,

8 Essa reserva tornouse uma estação de pesquisa de cientistas do MNRJ e acabou convertida em museu, que ganhou o nome de Mello Leitão (v. nota 1$)$. nem na vigilância, e menos ainda em pesquisa.

Outra reserva, criada no município de Santa Teresa, no Espírito Santo, mereceu a atenção do autor. Destacava ter sido ela criada por iniciativa da Sociedade dos Amigos do MNRJ, que comprou uma pequena área cuja flora e fauna seriam colocadas sob proteção (Leitão, 1940, p.195). ${ }^{8}$

O penúltimo capítulo de $A$ vida na selva enfocava a relação entre homem e floresta, incluindo um histórico dessa convivência desde 
os tempos pré-históricos até a contemporaneidade. Mello Leitão concluía declarando que, malgrado todo o avanço tecnológico, não havia possibilidade de o homem desvencilhar-se de sua relação umbilical com as florestas, pois "quer tratando-a como inimiga a destruir, quer venerando-a como nume próvido e tutelar, tem o homem vivido sempre na dependência estreita da selva" (Leitão, 1940, p.198). Segundo ele, o homem cobra um pesado tributo das florestas - abertura de campos de cultivo; caça; construção de casas, mobiliário e estradas de ferro; instalação de indústrias e as cidades, que usam a lenha para gerar calor, luz e energia. Porém o mesmo homem que dizima as florestas torna-se, muitas vezes, seu defensor.

Mello Leitão acreditava que o Estado tinha o dever de controlar o uso dos recursos naturais nas propriedades privadas. Alertava para o fato de que, no Brasil, a queimada e a derrubada das florestas ainda eram os principais métodos agrícolas. Enxergava, portanto, a necessidade de uma mudança de hábitos, para a qual as autoridades deveriam contribuir educando, investindo na pesquisa científica, fiscalizando, orientando a produção econômica para atividades e técnicas que não comprometessem os recursos naturais e a diversidade de espécies. O extrativismo e o aproveitamento dos frutos das árvores silvestres, por exemplo, constituíam, para o autor, modelos de iniciativa econômica compatível com a conservação das florestas.

\section{Zoogeografia e diversidade}

Nesta seção daremos uma breve notícia sobre o livro Zoogeografia do Brasil. No prefácio da primeira edição, de 1937, Mello Leitão esclarecia: "Precedido pela Fitogeografia do Prof. Alberto Sampaio, procurei ... aproveitar o mesmo plano, de modo a dar aos estudiosos de nossa natureza uma visão de conjunto harmônica e uniforme, significando o pensamento do Museu Nacional sobre a Biogeografia Brasileira" (Leitão, 1937b, p.7). O trecho indica a existência de um sentimento de grupo, entre os cientistas do MNRJ, em torno de um projeto de nacionalidade comprometido com o desenvolvimento do saber científico e a valorização da natureza. Na sua perspectiva, era necessário conhecer melhor o patrimônio natural do país para utilizá-lo de maneira racional e conservá-lo para as gerações vindouras (Franco, jan. 2002).

Referimo-nos aqui à segunda edição da obra, publicada em 1947, que o autor afirmava ser "um livro quase inteiramente novo, tais foram as correções, acréscimos e modificações que sofreu" (Leitão, 1947, p.5). Foi a obra de maturidade de Mello Leitão, que nele abordou a distribuição dos animais pelo Brasil a partir da distribuição mais ampla dos animais pelo planeta. 
O autor destacava a inserção da zoogeografia no âmbito de uma disciplina mais ampla, a biogeografia, e suas relações com outras ciências limítrofes. Talvez por isso ele tenha iniciado o livro com um histórico dessas ciências e de seus entrelaçamentos:

A Ecologia ou tratado das relações dos seres vivos entre si e com o meio em que vivem em condições de perfeita adaptação; a Biogeografia ou tratado da divisão da terra em regiões características pelo aspecto e distribuição dos seres vivos que lhes são peculiares; a Geonemiologia ou tratado da distribuição de grupos mais ou menos restritos de plantas ou de animais. (Leitão, 1947, p.7)

Mello Leitão abordava o estudo da distribuição geográfica dos animais desde Aristóteles e Plínio, passando pelos cronistas das grandes navegações e chegando até Buffon, autor da famosa História natural. Também a respeito do século XVIII, mencionava as obras de Zimmerman, o primeiro a demonstrar a importância geográfica da distribuição dos animais, e Lacepède, que relacionou as condições climáticas e o relevo de cada região com o desenvolvimento de sua fauna. No século XIX, segundo Mello Leitão, as concepções evolucionistas de Lyell, Darwin e Wallace impulsionaram os estudos zoogeográficos. Entre os principais pesquisadores da zoogeografia daquele século destacava Sclater, Wallace, Berghaus, Marshall, Forbes, Dana, Schmarda, Pucheran, Andrew Murray, Maurício Wagner, Semper, Agassiz, Blyth, Huxley, Blanford, Trouessart, Reichenow, Boulenger, Gunther, Woodward e Fischer (Leitão, 1947, p.13, 17).

No século XX, segundo Mello Leitão, os estudos zoogeográficos ganharam um perfil mais científico. Estabeleceram-se leis e princípios quanto à distribuição e às relações faunísticas. Eram citados como referências importantes Trouessart, Hesse, Arldt, Hermann Von Ihering, Marcus, Bodenheimer, Newbigin, Berghaus, Marshall, Bartholomew, Clarke, Grinshaw, Hans Krieg, Haake, Ortmann, Marc André, L. Joleaud, Fairfield Osborn, Charles Elton, Pearse, Frederic E. Clements, Victor E. Shelford, W.C. Allee, Rodolfo Von Ihering, Cabrera e Yepes. Essas longas listas de cientistas demonstram a erudição e atualização bibliográfica de Mello Leitão. Destaque-se que nessa obra não se encontram as mesmas críticas mordazes endereçadas a Darwin e à seleção natural, presentes em obras anteriores, o que pode representar um amadurecimento e aprofundamento do autor em relação aos debates acerca do tema.

Em três capítulos sobre conceitos básicos da zoogeografia, Mello Leitão examina "o hábitat e a influência dos outros seres; as leis gerais da dispersão e isolamento, com a formação de subespécies geográficas; a zoogeografia histórica” (Leitão, 1947, p.26). O ponto de partida era a própria definição da zoogeografia: "o estudo científico da vida animal, que trata das influências do meio, das mútuas 
${ }^{9}$ Sobre essa questão e os desdobramentos da ciência da ecologia, ver Acot, 1990, e Worster, 1994. relações entre as espécies animais e da sua distribuição pela terra, não só no momento atual como durante as eras geológicas". Dito isto, Mello Leitão esclarecia que "estão os seres, por sua própria constituição e necessidades alimentares, na dependência mais ou menos estreita do meio, cada habitat possuindo uma comunidade animal ou florística que lhe é peculiar" (p.26).

Não havia seres isolados na natureza. Os biomas se constituíam em uma teia de intrincadas relações entre os seres vivos e o seu meio. A análise do papel e do inter-relacionamento dos diversos fatores era, segundo Mello Leitão, a contribuição fundamental da ecologia para a zoogeografia. Tal percepção da organização da vida levava o nosso autor a simpatizar com a abordagem dos ecólogos norte-americanos A.G. Tansley, Frederic Clements e Victor Shelford, para os quais a natureza aparecia como um 'superorganismo vivo', capaz de se 'auto-regular' por meio da interação de seus diversos componentes. ${ }^{9}$

Mello Leitão defendia que a geonemiologia também desempenhava papel fundamental no estudo da distribuição geográfica dos animais, por dedicar-se à dispersão de espécies, gêneros ou, mais raramente, famílias. Observava que não havia região do globo com possibilidade de vida que não fosse desde logo ocupada por plantas e animais, embora a distribuição dos seres não fosse aleatória. Haveria barreiras de variados tipos, mas uma espécie poderia superar uma barreira e outra, usá-la como zona de transição, enquanto uma terceira seria de fato barrada. Assim, mares, topografia dos oceanos, rios, continentes, montanhas, desertos, variações climáticas, luminosidade, ventos e correntes, entre outros, contribuíam para definir a dispersão e o isolamento das diversas espécies. Essa mesma lógica era a responsável pelo processo diferenciação das espécies (especiação).

A distribuição descontínua atual de certos grupos de animais como, por exemplo, a das antas na América tropical e na Malásia e a incidência pontual de certos animais abundantes alhures explicavam-se pelo fato de ter existido, no passado, uma configuração diferente dos continentes e mares. Havia que atentar ainda para as rotas de migração das espécies e para o modo como determinados grupos povoaram novas regiões - por exemplo, a penetração dos carnívoros na América do Sul.

Seguem capítulos dedicados a vida aquática, influência do meio sobre os animais terrestres, divisões zoogeográficas e distribuição das respectivas faunas. O ponto de partida era a obra de Alfred Russel Wallace, Distribuição geográfica dos animais. Trouessart também era citado para esclarecer por que aves e mamíferos foram a base principal para o estabelecimento da sua divisão zoogeográfica (Leitão, 1947, p.275). 
Mello Leitão propunha os seguintes níveis de divisão, na distribuição dos animais: reino, região, sub-região, província e distrito. A sub-região Brasiliana (em que se encontraria o território brasileiro) e as suas províncias - Caribe, Amazônica ou Hiléia, CaririBororó, Tupi e Guarani - são objetos de vários capítulos de Zoogeografia do Brasil.

O último capítulo, "O homem e a zoogeografia", estuda "a influência do homem sobre a distribuição das faunas, quer como elemento perturbador, quer para a conservação de espécies ameaçadas de extinção" (Leitão, 1947, p.582). O autor acreditava que a influência humana sobre os outros seres era muitas vezes desastrosa. Em muitos casos, o extermínio de espécies era deliberado; em outros, porém, era involuntário, apesar dos resultados nefastos. Por isso, era importante estudar

as novas regiões criadas pela introdução consciente ou inconsciente de espécies estranhas à fauna local; a extinção de espécies nocivas por medidas de higiene e suas conseqüências zoogeográficas; a extinção total ou parcial de espécies animais (sobretudo aves e mamíferos) e o dique a ela oposto pelos parques e reservas; o resultado das culturas agrícolas sobre a zoogeografia, bem como o cosmopolitismo das faunas urbanas. (Leitão, 1947, p.583)

\section{Mello Leitão observava ainda:}

Por sua interferência cria o homem novos ambientes, novos biócoros e, portanto, uma distribuição zoogeográfica diversa: aqui estabelecendo raças locais, a formar híbridos e isolar mutações; ali a introduzir animais de outras regiões, que lhe modificam a fácies faunística própria; adiante a organizar ambientes de defesa, em condições ecológicas nem sempre idênticas às primitivas; quase sempre a quebrar esse sábio equilíbrio dos números das condições naturais, esquecido de que há uma estreita dependência entre os seres vivos, uma admirável harmonia, essa rede maravilhosa, cujas malhas não podem ser impunemente rotas. (Leitão, 1947, p.587)

Uma linha tênue ligava o cientista Mello Leitão ao romântico. Ele sabia que os equilíbrios naturais eram instáveis e tendiam a uma transformação constante, no sentido de uma diferenciação cada vez mais ampla das espécies. Contudo via ordem e harmonia nesse processo natural, e preocupava-se que a ação desinformada dos homens pusesse tudo a perder. A ciência tinha a missão de esclarecê-los.

A preocupação com a caça e perseguição de determinadas espécies de animais considerados nocivos era uma constante, pois "perseguindo uma espécie quebra o homem um dos elos da cadeia natural, e seu ato vai repercutir sobre todos os seres, que direta ou indiretamente estão ligados à espécie atingida" (Leitão, 1947, p.596). 
10 Sobre estes outros cientistas e escritores, ver os artigos de nossa autoria: Franco, Drummond, jan. 2005, set.-dez. 2005, jan.jun. 2005.
Por vários motivos o homem exterminou muitos animais ou reduziu suas populações: "Para tal extermínio serviu de pretexto a obtenção do alimento, o elemento de beleza para um adorno, a conquista de novas áreas para a agricultura ou o simples prazer de matar..." (p.598). Portanto a questão da conservação da natureza era urgentíssima para Mello Leitão. Ele defendia a silvicultura e a constituição de parques florestais, que "vieram restabelecer modernamente selvas em vias de desaparecimento, e proporcionar a instalação de habitantes habituais das matas, que já se tinham tornado raros" (p.596).

\section{Conclusão}

Para Mello Leitão, a biologia proporcionava ao mesmo tempo esclarecimento científico e contemplação estética, entrelaçando os ideais da razão iluminista e do transcendentalismo romântico. Ele defendia a necessidade de um projeto civilizador que reconciliasse o homem com o mundo natural, no qual ciência e Estado teriam responsabilidades a compartilhar, sobretudo no Brasil, ' país novo' que tentava construir a sua identidade nacional. Tal perspectiva era compartilhada por um grupo de cientistas, intelectuais e funcionários públicos, do qual ele fazia parte, que se mobilizou, nas décadas de 1930 e 1940, em torno da proteção da natureza brasileira. ${ }^{10}$

Como cientista prolífico e influente, Mello Leitão transmitiu, para várias gerações de cientistas brasileiros, seu saber sobre a natureza e sua preocupação com a preservação dela, décadas antes de a questão ambiental emergir de forma mais intensa na sociedade contemporânea. No entanto Mello Leitão e seus contemporâneos do MNRJ são, hoje, vozes quase esquecidas entre os que se manifestaram contra o tratamento irracional dispensado à natureza no Brasil. Contribui para isso o fato de praticamente toda a obra desses pensadores estar ausente dos catálogos das editoras e das estantes das livrarias. Ela é encontrada em números antigos de periódicos científicos, em livros que se tornaram raros ou em publicações avulsas de difícil acesso. Assim, não é de admirar que tenha caído sobre o pensamento e a ação de Mello Leitão, falecido há pouco menos de 60 anos, um preocupante manto que, se ainda não é de esquecimento, já beira o desconhecimento. E em termos de memória, o desconhecimento pode ser a véspera do esquecimento. 


\section{REFERÊNCIAS BIBLIOGRÁFICAS}

Acot, Pascal

1990

Alphandéry, Pierre; Bitoun, Pierre; Dupont, Yves

1992

Barbosa, Lívia Neves de Holanda; Drummond, José Augusto

1994

Dean, Warren 1996

Desmond, Adrian;

Moore, James

2000

Diamond, Jared 2002

Drummond, José Augusto 1999

Duarte, Regina Horta 2005

Duarte, Regina Horta jul.-dez. 2000

Faulhaber, Priscila; Toledo, Peter Mann de (Org.)

Franco, José Luiz de Andrade jan. 2002

Franco, José Luiz de Andrade

Franco, José Luiz de Andrade; Drummond, José Augusto

$$
\text { jan. } 2005
$$

Franco, José Luiz de Andrade; Drummond, José Augusto set.-dez. 2005

Franco, José Luiz de Andrade; Drummond, José Augusto jan.-jun. 2005
História da ecologia.

Rio de Janeiro: Campus.

O equívoco ecológico: riscos políticos.

São Paulo: Brasiliense.

Os direitos da natureza numa sociedade relacional

Revista Estudos Históricos, Rio de Janeiro, v.7, n.14, p.265-389.

A ferro e fogo.

São Paulo: Companhia das Letras.

Darwin: a vida de um evolucionista atormentado.

São Paulo: Geração Editorial.

Armas, germes e aço: os destinos das sociedades humanas. Rio de Janeiro: Record.

A legislação ambiental brasileira de 1934 a 1988: comentários de um cientista ambiental simpático ao conservacionismo. Ambiente $\mathcal{E}$ Sociedade, Campinas, v.2, p.127-149.

Biologia e sociedade no Brasil dos anos 1930: práticas de escrita e divulgação científica em Cândido de Mello Leitão. In: Figueiredo, Betânia Gonçalves; Condé, Mauro Lúcio Leitão (Org.). Ciência, história e teoria. Belo Horizonte: Argumentum. p.13-40.

Nação, natureza e território.

Cândido de Mello Leitão e a biologia no Brasil. Territórios e fronteiras, v.1, n.1, p.141-56.

Conhecimento e fronteira: história da ciência na Amazônia.

Belém: Museu Paraense Emílio Goeldi.

A Primeira Conferência Brasileira de Proteção à Natureza e a questão da identidade nacional. Varia Historia (Dossiê História e Natureza), Belo Horizonte, n.26, p.77-96.

Proteção à natureza e identidade nacional: 1930-1940.

Tese (Doutorado) - Departamento de História, Universidade de Brasília, Brasília.

Alberto José Sampaio: um botânico brasileiro e o seu programa de proteção à natureza. Varia História, Belo Horizonte, v.33, p.129-159.

Armando Magalhães Corrêa: gente e natureza de um sertão quase metropolitano. História, Ciências, Saúde - Manguinhos, Rio de Janeiro, v.12, n.3, p.1033-1059.

Frederico Carlos Hoehne: a atualidade de um pioneiro no campo da proteção à natureza no Brasil. Ambiente $\mathcal{E}$ Sociedade, Campinas, v.8, n.1, p.141-166. 


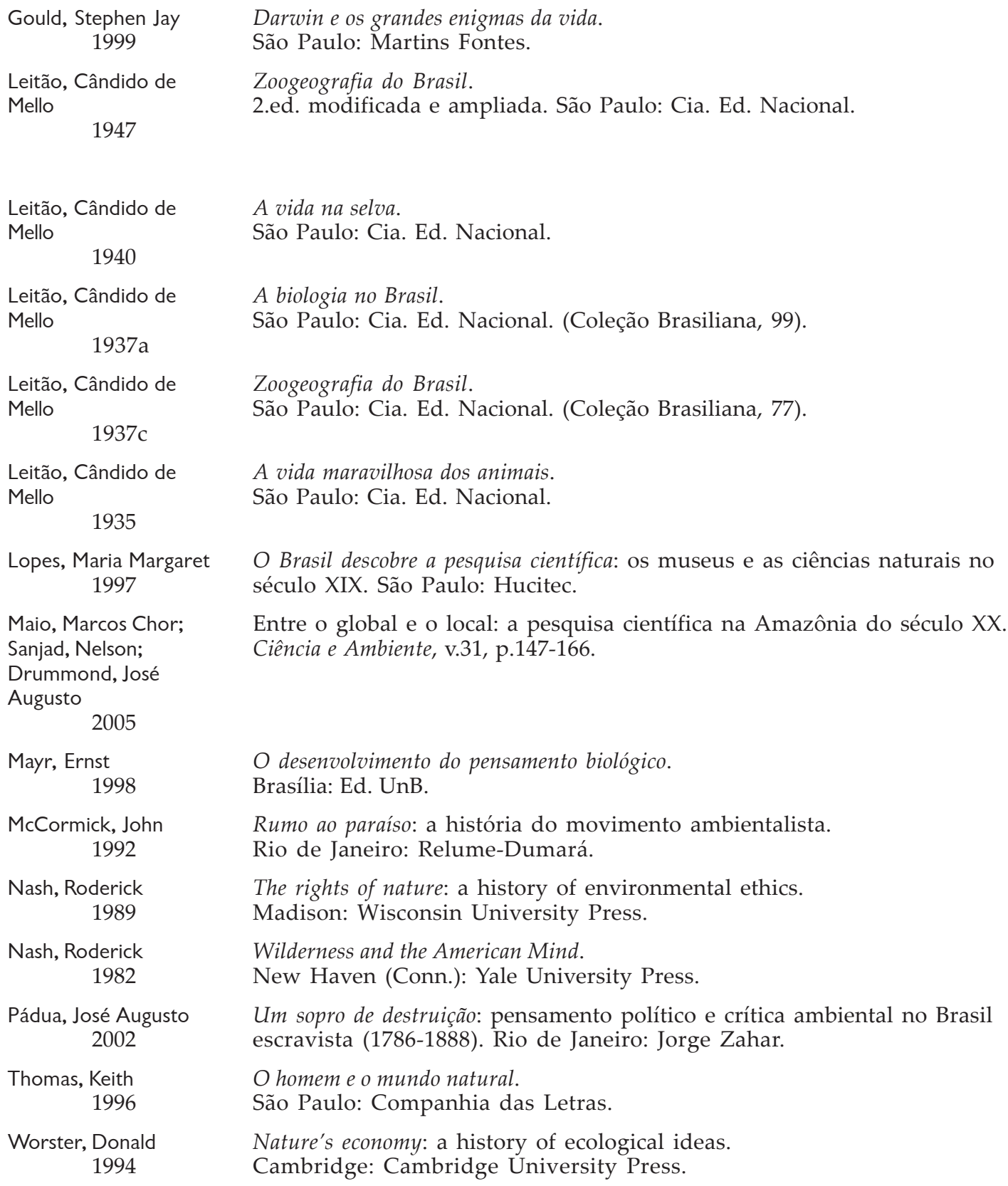

O Brasil descobre a pesquisa científica: os museus e as ciências naturais no século XIX. São Paulo: Hucitec.

Entre o global e o local: a pesquisa científica na Amazônia do século XX. Ciência e Ambiente, v.31, p.147-166.

O desenvolvimento do pensamento biológico.

Brasília: Ed. UnB.

Rumo ao paraíso: a história do movimento ambientalista. Rio de Janeiro: Relume-Dumará.

The rights of nature: a history of environmental ethics. Madison: Wisconsin University Press.

Wilderness and the American Mind. New Haven (Conn.): Yale University Press.

Um sopro de destruição: pensamento político e crítica ambiental no Brasil escravista (1786-1888). Rio de Janeiro: Jorge Zahar.

O homem e o mundo natural.

São Paulo: Companhia das Letras.

Nature's economy: a history of ecological ideas.

Cambridge: Cambridge University Press.

Recebido para publicação em setembro de 2006. Aprovado para publicação em abril de 2007. 